\title{
The Impact of Shift Work on Brazilian Train Drivers with Different Chronotypes: A Comparative Analysis through Objective and Subjective Criteria
}

\author{
Silvio de Araújo Fernandes Jr. ${ }^{a} \quad$ Leandro Stetner Antonietti ${ }^{a} \quad$ Amanda Saba $^{a}$ \\ Alexandre Paulino de Faria ${ }^{a} \quad$ Andrea Maculano Esteves ${ }^{c}$ Sergio Tufik ${ }^{b}$ \\ Marco Túlio de Mello ${ }^{a, b}$ \\ ${ }^{a}$ Centro de Estudo Multidisciplinar em Sonolência e Acidentes (CEMSA), and b Departamento de Psicobiologia, \\ Universidade Federal de São Paulo, São Paulo, and ${ }^{C}$ Faculdade de Ciências Aplicadas, Universidade Estadual de \\ Campinas, Limeira, Brazil
}

\section{Key Words}

Chronotype - Fatigue - Shift work - Psychomotor Vigilance Task · Actigraphy

\begin{abstract}
Objective: The aim of this study was to compare sleep pattern, tiredness sensation and quality of life between different chronotypes in train drivers from a Brazilian transportation company. Subjects and Methods: Ninety-one train drivers, working a rotary work schedule including night shift, were divided into three groups according to their chronotype (morning types, intermediate or evening types) and were assessed for their sleep and quality of life, as characterized by a subjective questionnaire and the Psychomotor Vigilance Task (PVT), applied before and immediately after the night shift. The pattern of activity and rest was measured for 10 days by actigraphy, and the chronotype was determined through the Morningness-Eveningness Questionnaire. Results: Forty-one (45.1\%) individuals were classified as morning type, 44 (48.4\%) were classified as intermediate and 6 $(6.6 \%)$ as evening type. The evening types had a tendency to remain awake for a longer period of time before the night
\end{abstract}

\begin{tabular}{ll}
\hline KARGER & $\begin{array}{l}\text { ( } 2013 \text { S. Karger AG, Basel } \\
1011-7571 / 13 / 0224-0390 \$ 38.00 / 0 \quad \text { Karger }\end{array}$ \\
E-Mail karger@karger.com & $\begin{array}{l}\text { This is an Open Access article licensed under the terms of the } \\
\text { www.karger.com/mpp }\end{array}$ \\
& $\begin{array}{l}\text { Creative Commons Attribution-NonCommercial 3.0 Un- } \\
\text { ported license (CC BY-NC) (www.karger.com/OA-license), } \\
\text { applicable to the online version of the article only. Distribu- } \\
\text { tion permitted for non-commercial purposes only. }\end{array}$
\end{tabular}

shift $(p=0.05)$ and scored worse overall for quality of life compared to morning types $(p=0.11)$. There was no significant difference between the groups regarding variability in the PVT performance, even when covaried by the period of waking time before the test. There was no significant difference either in feelings of fatigue before and after starting the shift. Conclusion: Although the evening type number was small, evening type individuals scored worse relative to sleep and quality of life than morning type individuals.

Copyright $\odot 2013$ S. Karger AG, Basel

\section{Introduction}

Several physiological and psychological functions in humans show circadian variations. The endogenous timing system, also known as the biological clock, generates physiological and behavioral changes and represents a component of interindividual variation [1]. In this context, individual preferences concerning sleep habits and activity may be used to classify groups of individuals according to their chronotype: morning types, intermediate or evening types [2]. This classification refers to invol- 
untary biological tendencies relating to the need to perform work or social activities and sleep during certain times of day [3].

Chronotype may be an important predictor of habitual sleep patterns in humans [4] because the intrinsic circadian period may change between individuals, and the assessment of the phase of circadian rhythms provides information about the temporal organization of endogenous regulatory processes. Thus, subjective questionnaires for morningness and eveningness were devised in an attempt to estimate these individual differences [4].

Evening type individuals tend to have a circadian delay with regard to activity and sleep habits, shifting their activity peak to the later hours of the day and the start of sleep towards the evening. Conversely, morning types show activity peaks in the early hours of the day $[5,6]$.

Other endogenous variables associated with alertness and subjective sleepiness showed differences between the chronotypes, such as body temperature [4] and the peak of cortisol in morningness individuals, with acrophases (peak times), approximately $55 \mathrm{~min}$ for cortisol and 68 min for body temperature [7].

The level of tolerance for a rotary work schedule or night shift is also influenced by individual differences and can be evaluated by quality of sleep, alertness and subjective factors. These variables affect levels of alertness, errors and overall performance, increasing the risk of accidents at work [8].

In general, changes in sleep pattern, usually observed in shift workers, can affect the quality of life as it relates to the ability to adapt to social, physiological and psychological changes [9]. Similarly, the circadian type or chronotype can potentially alleviate or exacerbate the negative effects of changes in the wake-sleep cycle [10]. Consequently, a better understanding of issues such as fatigue, excessive sleepiness and sleep disorders in workers has become the focus of great interest because these factors are associated with an increased risk for accidents at work. Thus, the aim of this study was to assess the influence of chronotype in train drivers by objective and subjective variables through the comparison of total sleep time, sleep efficiency, reaction time, attention lapses and quality of life, between these workers.

\section{Subjects and Methods}

The initial sample consisted of 128 male train drivers aged 23-60 years $(34.4 \pm 9.0)$ with a BMI mean of $26.76 \pm 3.51$. The assessments took place between March and October of 2010. The work shift schedule of the sampled subjects consisted of 4 days of work with $60 \mathrm{~h}$ off. They worked $6 \mathrm{~h}$ per day in a rotary schedule with counterclockwise direction (6:00 p.m. to 12:00 a.m; 12:00 a.m. to 6:00 a.m.; 6:00 a.m. to 12:00 p.m.; 12:00 p.m. to 6:00 p.m.).

Exclusion criteria were individuals who studied during the interval between work shifts, or took naps during the period before shifts or both. The presence of sleep disorders was not an exclusion criterion because it was observed that these disorders were homogeneously distributed among the groups in the sample. After the selection process, 28 individuals were excluded for taking naps in the period preceding the shift in which they were evaluated. Eight others were excluded for studying during the interval between shifts and 1 individual was excluded for both napping and studying. Therefore, the final sample consisted of 91 individuals, all male. The study was approved by the Research Ethics Committee at the Universidade Federal de São Paulo, Brazil.

\section{Experimental Design}

In this protocol, 4 evaluations per night were performed. The assessment of the first individual started at 7 p.m. All subjects began their battery of tests by responding to a general questionnaire that gathered personal and work schedule information as well as questionnaires regarding sleep, quality of life and chronotype. The questionnaires for quality of life and chronotype were completed between 7:30 and 8:30 p.m. After this, the anthropometric parameters were evaluated and the placement of activity and rest monitors (actigraphy) were performed.

At the end of these assessments, the subjects were conducted to a room suitable for polysomnography (PSG) to investigate possible sleep disturbances. On the night of the PSG examination (from 10 to 11 p.m.), the individuals received an actigraphy monitor and instructions on its use, such as how to correctly fill out their sleep diary. The actigraph was configured to start collecting data at 11:59 p.m. of the same night. After 10 consecutive days, the equipment was collected for the analysis of the data.

In the second stage, the subjects performed the Psychomotor Vigilance Task (PVT). Each subject was assessed on 2 tests at 2 different times in a single day. The tests were performed minutes before the start of the workday and just after the end of the shift. However, this task was never applied on the first workday to avoid the 'day off effect' in the results. Subjective and objective criteria were selected for the assessment of fatigue and chronotype. The individuals were divided into three groups according to their chronotype: morning, intermediate and evening types.

\section{Subjective Criteria}

Chronotype. To ascertain the chronotype, the subjects answered 19 questions in the questionnaire developed by Horne and Ostberg [2], which had been translated into Portuguese and previously validated [11]. The sum of the questions yields a score ranging from 16 to 86 points, with lower values corresponding to evening chronotypes [3].

Sleep. The UNIFESP sleep questionnaire developed by Braz et al. [12] and validated by Pires et al. [13] was used to describe general sleep habits. The Portuguese language version of the Epworth Sleepiness Questionnaire [14] was used to assess sleepiness in daily activities.

Quality of Life. In this protocol, the validated Portuguese version of the SF-36 [15] was used to analyze the impact of shift work on the quality of life. 
Sensation of Fatigue. A visual analogue scale ranging from 0 to 10 points, where 0 represents no fatigue and 10 represents the maximum feeling of tiredness, was used to evaluate the sensation of fatigue before and after the shift.

\section{Objective Criteria}

Psychomotor Vigilance. The PVT equipment was used to measure the reaction time and number of lapses. This simple tool analyzes the time required for a motor reaction to occur in response to visual or sound stimuli. During the test sessions, visual stimuli appeared on the screen at intervals of 2-10 s. If the individuals had a reaction time greater than $500 \mathrm{~ms}$, the response was considered an attention failure and characterized as a lapse [16]. The location of the testing was the workplace itself, adapted so that external stimuli did not interfere with the results. During the tests, the individual remained in the room alone.

Polysomnography. To rule out any sleep disorders and determine the macrostructure of sleep, all volunteers were submitted to PSG on the last night of their day off prior to the first workday. The PSG was performed in a hotel room fully equipped and suitable for this purpose. PSG was used primarily to discard sleep disorders, but it is also sensitive to sleep-disordered breathing. To characterize the possible sleep disorders, the PSG examination was conducted with a portable system (Titanium ${ }^{\mathrm{TM}}$-Embla Systems, Broomfield, Colo., USA). The classification of sleep stages and arousals followed the recommendations of the American Academy of Sleep Medicine using the alternative rule for hypopnea [17].

Actigraphy (Pattern of Activity and Rest). Activity, which was recorded using an acceleration or actigraphy monitor (model Actiwatch-64; Philips/Respironics ${ }^{\circledR}$, Andover, Mass., USA), was used to assess the circadian distribution pattern related to daily activities (sleep and rest periods). Actigraphy is considered a valid procedure to measure the pattern of motor activity [18] and the rhythm of the wake/sleep cycle, allowing for the classification of possible circadian disorders [19]. The use of the actigraphy monitor allowed for the evaluation of the pattern of the sleep and wake cycle and the total time, latency, sleep efficiency, and maximum time awake over the 10 days.

\section{Statistical Analysis}

The SPSS Statistics 17.0 software for Windows (SPSS, Inc.) was used for the analysis. The normality of the data was assessed with the Kolmogorov-Smirnov test. The lapses of attention in the PVT test were transformed using the formula $(\sqrt{ } n)+(\sqrt{ } n+1)$, where $n$ represents the number of lapses, to obtain an approximately Gaussian distribution. The descriptive statistics consisted of the calculation of the mean \pm standard deviation for the quantitative data. The comparison between the groups for this type of data was performed using a one-way ANOVA with a least significant difference post hoc test when appropriate. The homoscedasticity was tested using the Levene test, and when necessary, the Brown-Forsythe correction was used. A repeated-measures ANOVA (time $\times$ group) was used in the comparisons between groups involving the moments before and after the workday. The data were adjusted using an ANCOVA whenever the waking time preceding the workday would influence the outcome of the comparison between groups. The effect size (ES) and power of the test were calculated for those analyses. The descriptive statistics for the qualitative data consisted of calculating the absolute and relative frequencies and comparisons between groups were performed using the Pearson $\chi^{2}$ test. The value of $\alpha=5 \%$ was considered to be statistically significant.

\section{Results}

Of the 91 individuals tested, 41 (45.1\%) were morning types, $44(48.4 \%)$ were intermediate and $6(6.6 \%)$ were evening types. Among the morning types, 7 (17.0\%) were extreme morning types and $34(83 \%)$ were moderate morning types. All of the evening types were classified as moderate evening types. Considering BMI, 26 (28.6\%) individuals were classified as normal, 54 (59.3\%) were overweight and $11(12.1 \%)$ were obese. The external variables, such as working time (in years) in the work shift schedules, were homogeneous, in other words, without significant difference between the chronotypes.

Regarding age, morning types were significantly older than intermediate types $(37.10 \pm 10.60$ vs. $32.41 \pm 6.68$ years, respectively, $\mathrm{p}=0.016)$. However, evening types (30.50 \pm 8.83 years) did not differ statistically from the other groups. The average age of this sample corresponded with the classification of young adults. Therefore, no significant changes related to the chronotype and sleep patterns that usually occur during adolescence and senility were considered. Obstructive sleep apnea syndrome identified by PSG examination was evenly distributed between the chronotypes, with no significant differences between the types.

Intermediate chronotypes showed longer waking times before the night shift compared to both morning and evening types. Evening types, in turn, displayed a trend towards significantly more waking time before the work shift compared to the morning types. It is important to note that the time awake before the day's work was included as a subjective assessment because it is a time stated by the individual before applying the PVT test. The subjective feelings of sleepiness and fatigue were not significantly different between the chronotypes. Likewise, there were no statistically significant differences between the change in feelings of fatigue assessed by the visual analogue scale before and after the shift (interaction). There was a time effect of this variable in the analysis $(\mathrm{p}<0.001$; ES $=0.546$; power $=1.00)$, but there was no group effect $(\mathrm{p}=0.916$; $\mathrm{ES}=0.002$; power $=0.063)(\mathrm{ta}-$ ble 1).

As shown in table 2, there was no significant difference between the groups regarding the change in performance in PVT testing (interaction), both when measured 
Table 1. General summary of the results of the subjective analysis

\begin{tabular}{|c|c|c|c|c|c|c|c|}
\hline & \multicolumn{3}{|l|}{ Group } & \multicolumn{4}{|c|}{ Statistic } \\
\hline & $M(n=41)$ & $\operatorname{In}(n=44)$ & $E(n=6)$ & ST & $\mathrm{p}$ & ES & power \\
\hline Wake time before work, $\mathrm{h}$ & $3.70 \pm 2.45$ & $4.73 \pm 2.13^{c}$ & $5.67 \pm 1.99$ & 3.299 & 0.042 & 0.070 & 0.612 \\
\hline General score SF-36, \% & $80.52 \pm 7.66$ & $75.03 \pm 12.83^{c}$ & $73.19 \pm 7.44$ & 3.353 & 0.040 & 0.072 & 0.619 \\
\hline Functional capacity SF-36, \% & $91.83 \pm 9.92$ & $88.52 \pm 16.86$ & $90.83 \pm 9.17$ & 0.623 & 0.539 & 0.014 & 0.151 \\
\hline Physical aspects SF-36a $\%$ & $95.12 \pm 11.48$ & $86.93 \pm 26.13$ & $87.50 \pm 20.92$ & 1.784 & 0.195 & 0.039 & 0.363 \\
\hline Pain SF-36, \% & $85.27 \pm 16.84$ & $78.16 \pm 21.25$ & $75.33 \pm 16.42$ & 0.771 & 0.176 & 0.039 & 0.362 \\
\hline General state of health SF-36, \% & $85.00 \pm 12.98$ & $81.95 \pm 15.59$ & $75.00 \pm 11.40$ & 1.453 & 0.240 & 0.032 & 0.303 \\
\hline Vitality SF-36a $\%$ & $45.13 \pm 4.74$ & $43.98 \pm 7.20$ & $46.67 \pm 8.76$ & 0.482 & 0.629 & 0.015 & 0.159 \\
\hline Social aspects SF-36, \% & $92.19 \pm 16.67$ & $86.36 \pm 19.03$ & $79.17 \pm 23.27$ & 1.893 & 0.157 & 0.042 & 0.384 \\
\hline Emotional aspects SF-36a $\%$ & $93.50 \pm 17.02$ & $85.61 \pm 26.31$ & $83.33 \pm 27.89$ & 1.229 & 0.322 & 0.033 & 0.309 \\
\hline Mental health SF-36, \% & $62.60 \pm 5.62$ & $61.64 \pm 7.44$ & $59.33 \pm 3.93$ & 0.733 & 0.483 & 0.017 & 0.171 \\
\hline Sleepiness & & & & 1.352 & 0.509 & - & - \\
\hline Without & $33(80.5)$ & $31(70.5)$ & $4(66.7)$ & & & & \\
\hline With & $8(19.8)$ & $13(29.5)$ & $2(33.3)$ & & & & \\
\hline Feeling of tiredness ${ }^{b}$ & & & & 0.454 & 0.637 & 0.010 & 0.122 \\
\hline Before work & $2.27 \pm 1.94$ & $2.41 \pm 1.96$ & $1.67 \pm 1.63$ & & & & \\
\hline After work & $5.66 \pm 2.33$ & $5.55 \pm 1.99$ & $5.67 \pm 1.97$ & & & & \\
\hline
\end{tabular}

Data are presented as the mean \pm standard deviation or as the absolute frequency (relative frequency \%).

$\mathrm{M}=$ Morning types; $\mathrm{In}=$ intermediate; $\mathrm{E}$ = evening types; $\mathrm{ST}$ = statistical test.

${ }^{a}$ It was necessary to use the Brown-Forsythe correction. ${ }^{b}$ The statistics were presented in the table due to an interaction. Time effect $(\mathrm{p}<0.05) .{ }^{\mathrm{c}}$ Statistically significant difference compared to the morning types $(\mathrm{p}<0.05)$.

Table 2. Results of the objective analysis - PVT

\begin{tabular}{|c|c|c|c|c|c|c|c|}
\hline & $\mathrm{M}(\mathrm{n}=41)$ & $\operatorname{In}(n=44)$ & $E(n=6)$ & ST & $\mathrm{p}$ & ES & power \\
\hline Before work & $1.61 \pm 0.97$ & $1.45 \pm 0.72$ & $2.28 \pm 1.87$ & & & & \\
\hline After work & $1.73 \pm 1.16$ & $1.83 \pm 1.10$ & $2.13 \pm 1.37$ & & & & \\
\hline Median reaction time ${ }^{\mathrm{a}, \mathrm{b}}, \mathrm{ms}$ & & & & 0.902 & 0.410 & 0.020 & 0.201 \\
\hline
\end{tabular}

Data are presented as the mean \pm standard deviation. $\mathrm{M}=$ Morning types; $\mathrm{In}=$ intermediate; $\mathrm{E}=$ evening types; $\mathrm{ST}=$ statistical test. It was necessary to use the Brown-Forsythe correction.

a The statistics are presented in the table due to an interaction. ${ }^{b}$ Time effect $(p<0.05)$.

by the number of lapses of attention and when measured by the median reaction time. There was also no time effect when comparing the number of lapses $(\mathrm{p}=0.522$; $\mathrm{ES}=0.005$; power $=0.097)$ or a group effect $(\mathrm{p}=0.319$; $\mathrm{ES}=0.026$; power $=0.248$ ). There was, however, a time effect when comparing the median reaction time ( $\mathrm{p}<$ 0.001 , ES $=0.175$; power $=0.990)$, but there was no group effect $(\mathrm{p}=0.396$; $\mathrm{ES}=0.021$; power $=0.208)$. Co- variance with waking time before the shift showed the same lack of effect for the number of lapses of attention, and the time effect became nonsignificant in the analysis of the median reaction time.

Based on the actigraphy, the average total sleep time of evening types (4.98 $\pm 0.61 \mathrm{~h}$ ) was somewhat higher than that of intermediate types $(4.60 \pm 0.81 \mathrm{~h})$ and morning types $(4.52 \pm 0.77 \mathrm{~h})$; however, the differences were not 
Table 3. Actigraphy results

\begin{tabular}{|c|c|c|c|c|c|c|c|}
\hline & \multicolumn{3}{|l|}{ Group } & \multicolumn{4}{|c|}{ Statistic } \\
\hline & $M(n=40)$ & $\operatorname{In}(n=42)$ & $E(n=6)$ & ST & $\mathrm{p}$ & ES & power \\
\hline Sleep time, $\mathrm{h}$ & $4.52 \pm 0.77$ & $4.60 \pm 0.81$ & $4.98 \pm 0.61$ & 0.929 & 0.399 & 0.021 & 0.206 \\
\hline Sleep latency, min & $10.13 \pm 6.56$ & $10.90 \pm 6.92$ & $9.53 \pm 2.91$ & 0.202 & 0.817 & 0.005 & 0.081 \\
\hline
\end{tabular}

Data are presented as the mean \pm standard deviation. $\mathrm{M}=$ Morning types; $\mathrm{In}=$ intermediate; $\mathrm{E}=$ evening types; $\mathrm{ST}=$ statistical test. The actigraphy results for 3 employees ( 2 intermediate and 1 morning types) were defined as inconclusive due to excessive removal of the equipment during the 10 days of use. Therefore, they were excluded from the actigraphy analysis.

significant (table 3). Regarding sleep efficiency, individuals showed an average of $81.21 \pm 5.22$ in evening types, $80.32 \pm 4: 59$ in intermediate types and $77.59 \pm 6.51$ in morning types, with no significant difference between groups $(\mathrm{p}=0.6, \mathrm{ES}=0064$, power $=0553)$. In this sample, the latency of sleep also showed no significant difference between groups.

The results of the subjective assessments as listed in table 1 showed that morning types had higher overall quality of life (SF-36) scores compared to intermediate and evening types. The scores related to physical aspects (morning types $95.12 \pm 11.48$ and evening types $87.50 \pm$ 20.92) and emotional aspects (morning types $93.50 \pm$ 17.02 and evening types $83.33 \pm 27.89$ ) showed significant differences, with evening types having the worse indices.

\section{Discussion}

The chronotype distribution of $6.6 \%$ evening types, $45.1 \%$ morning types and $48.4 \%$ intermediates of this study is similar to that of previous studies [20,21]. Taillard et al. [20] had reported a distribution of $40.2 \%$ morning types and $10 \%$ evening types in 2,000 adults, while Taillard et al. [21] reported a distribution of $48 \%$ moderate morning types, $40.3 \%$ intermediate and $2.2 \%$ moderate evening types in 1,165 middle-aged workers.

Our finding that the pattern of chronotype changes is based on age confirmed the findings of a previous study that there is a phase delay during adolescence, increasing eveningness, and there is a phase advance in advanced age that increases morningness [22] compared to young adults.

Gamble et al. [23] analyzed 388 shift workers and concluded that the influence of phenotypes and genotypes (chronotypes, circadian gene polymorphisms and envi- ronmental influence) contributed to the adaptation to circadian changes resulting from shift work schedules. Evening type people could adjust more easily to night work compared to morning type individuals, who have a circadian phase advance [24]. However, in this study, a difficulty to adjust to the rotary shift was observed when evening type individuals were assessed by actigraphy. An improvement in the result of tests for reaction time and subjective scores related to quality of life was not observed.

According to Akerstedt and Wright [9], shift work and night work cause negative effects on sleep, subjective sleepiness and psychomotor performance, which can be measured by vigilance tasks and reaction time. In this study, psychomotor performance, as well as reaction time and attention lapses, were not significantly different among the chronotypes, which may be explained by the fact that the volunteers were not totally deprived of sleep. Several other studies have validated or used actigraphy to measure variables, such as sleep efficiency and total sleep time $[25,26]$.

The total sleep time as well as the usual time of sleep onset showed individual variation [26] related to age, the kind of work and individual preferences according to chronotype. Since all subjects in our sample worked according to the same working schedule model (rotary in the counterclockwise direction), opportunities to sleep depended upon working hours regardless of chronotype, so that no group showed a statistical difference in total sleep time (morning types 4:52 $\pm 0.77,4.60 \pm 0.81$ intermediate and evening types $4.98 \pm 0.61$ ) (table 3 ).

Evening types in this sample showed a tendency toward longer waking times before the beginning of the shift (5.67 $\pm 1.99 \mathrm{~h})$ and a longer maximum time awake (23.29 \pm 10.76 consecutive hours) compared to the other chronotypes, as measured by actigraphy. Additionally, in 
the study by Taillard et al. [20] that sought to assess the sleep needs of different chronotypes, eveningness was associated with an increased need for sleep, irregular sleep habits and a higher consumption of caffeine to stay awake. In addition, evening types were associated with a greater sleep debt during the week and an increased need for extended sleep during the weekends. However, evening type individuals of this sample did not show lower values of sleep latency compared to morning type individuals during the consecutive assessment for 10 days (table 3), which may suggest that evening type individuals did not show the largest sleep debit throughout the week work. Similarly, there is no significant difference in the sensation of sleepiness or tiredness between the chronotypes (table 1).

Subjective instruments, such as self-reporting questionnaires that measure the levels of health and quality of life in shift workers, are often used in various studies. Tepas et al. [27] used questionnaires to assess the sense of physical and mental fatigue after the final shift of 865 individuals to evaluate the well-being and quality of life in shift workers of different nationalities and concluded that night shift workers had, despite some regional differences between nationalities, greater feelings of tiredness after the workday. In this study, in the questionnaire regarding quality of life (SF-36), evening types showed a tendency for worse overall scores compared to morning and intermediate chronotypes. Also related to the scores of physical (morning types $95.12 \pm 11.48$ and evening types 87.50 \pm 20.92 ) and emotional aspects (morning types $93.50 \pm$ 17.02 and evening types $83.33 \pm 27.89$ ), evening type individuals showed a significantly worse index.
Although this study provides relevant findings, it is important to call attention to its limitations. First, the disproportionate sizes of the groups may have caused potential differences to lose statistical significance. Additionally, the need to exclude individuals who napped or studied during data collection could have created a condition that is not fully consistent with the reality of shift workers, especially younger workers, but the procedure was necessary to normalize the sample in this study. Another limitation of this protocol was that the results presented in this study cannot be extrapolated to females, children or the elderly.

\section{Conclusion}

The evening type workers in this sample did not show better rates of fatigue before or after a work shift or better performance on the PVT when evaluated for a rotary work schedule. Thus, in the specific population studied, the results suggest that even during the night period, evening types showed worse scores related to the sleep and quality of life compared to the morning type individuals.

\section{Acknowledgments}

This work was supported by grants from the Universidade Federal de São Paulo, Associação Fundo de Incentivo à Pesquisa, FAPESP (CEPID No. 98/14303-3 to S.T.), Centro Multidisciplinar em Sonolência e Acidentes (CEMSA), Conselho Nacional de Desenvolvimento Científico e Tecnológico $(\mathrm{CNPq})$ and Centro de Estudo em Psicobiologia e Exercício (CEPE).

\section{References}

1 Moore RY: Circadian rhythms: basic neurobiology and clinical applications. Annu Rev Med 1997;48:253-266.

- 2 Horne JA, Ostberg O: A self-assessment questionnaire to determine morningnesseveningness in human circadian rhythms. Int J Chronobiol 1976;4:97-110.

-3 Sack RL, Auckley D, Auger R, Carskadon MA, Wright Jr KP, Vitiello MV, Zhdanova IV: Circadian rhythm sleep disorders. 1. Basic principles, shift work and jet lag disorders. An American Academy of Sleep Medicine review. Sleep 2007;30:1460-1483.

-4 Kerkhof GA: Inter-individual differences in the human circadian system: a review. Biol Psychol 1985;20:83-112.
5 Taillard J, Philip P, Chastang JF, Bioulac B: Validation of Horne and Ostberg morningness-eveningness questionnaire in a middleaged population of French workers. J Biol Rhythms 2004;19:76-86.

-6 Mongrain V, Carrier J, Dumont M: Circadian and homeostatic sleep regulation in morningness-eveningness. J Sleep Res 2006; 15:162-166.

7 Bailey SL, Heitkemper MM: Circadian rhythmicity of cortisol and body temperature: morningness-eveningness effects. Chronobiol Int 2001;18:249-261.

8 Fido A, Ghali A: Detrimental effects of variable work shifts on quality of sleep, general health and work performance. Med Princ Pract 2008; 17:453-457.
9 Akerstedt T, Wright KP: Sleep loss and fatigue in shift work and shift work disorder. Sleep Med Clin 2009;4:257-271.

10 Waterhouse JM, Folkard S, Minors DS: Shiftwork, Health and Safety: An Overview of the Scientific Literature 1978-1990. London, Her Majesty's Stationery Office, 1992.

11 Benedito-Silva AA, Menna-Barreto LS, Marques N, Tenreiro S: A self-assessment questionnaire for the determination of morningness-eveningness types in Brazil; in Hayes DK, Pauly JE, Reiter RJ (eds): Chronobiology: Its Role in Clinical Medicine, General Biology and Agriculture, Part B. New York, Wiley-Liss, 1990, pp 89-98. 
12 Braz S, Neumann BRB, Tufik S: Evaluation of sleep disorders: elaboration and validation of a questionnaire. Rev ABP-APL 1987;9:914.

-13 Pires MLN, Benidito-Silva AA, De Mello MT, Del Giglio S, Pompéia C, Tufik S: Sleep habits and complaints of adults in the city of São Paulo, Brazil, in 1987 and 1995. Braz J Med Biol Res 2007;40:1505-1515.

14 Bertolazi AN, Fagondes SC, Hoff LS, Pedro VD, Menna Barreto SS, Johns MW: Portuguese-language version of the Epworth sleepiness scale: validation for use in Brazil. J Bras Pneumol 2009;35:877-883.

15 Da Mota FD, Ciconelli RM, Ferraz MB Translation and cultural adaptation of quality of life questionnaires: an evaluation of methodology. J Rheumatol 2003;30:379385.

16 Banks S, Van Dongen HPA, Maislin G, Dinges DF: Neurobehavioral dynamics following chronic sleep restriction: dose-response effects of one night for recovery. Sleep 2010;33: 1013-1026.
17 Iber C, Ancoli-Israel S, Chesson A Jr, Quan S: The AASM Manual for the Scoring of Sleep and Associated Events: Rules, Terminology and Technical Specification. Westchester, American Academy for Sleep Medicine, 2007.

18 McPartland RJ, Kupfer DJ, Foster FG, Reisler KL, Matthews G: Objective measurement of human motor activity: a preliminary normative study. Biotelemetry 1975;2:317-323.

19 Ancoli-Israel S, Cole R, Alessi C, Chambers M, Moorcroft W, Pollak CP: The role of actigraphy in the study of sleep and circadian rhythms. Sleep 2003;26:342-392.

20 Taillard J, Philip P, Bioulac B: Morningness/ eveningness and the need for sleep. J Sleep Res 1999;8:291-295.

21 Taillard J, Philip P, Chastang JF, Diefenbach $\mathrm{K}$, Bioulac B: Is self-reported morbidity related to the circadian clock? J Biol Rhythms 2001;16:183-190.

22 Chelminski I, Ferraro R, Petros TV, Plaud JJ: Horne and Ostberg questionnaire: a score distribution in a large sample of young adults. Person Individ Diff 1997;23:647-652.
23 Gamble KL, Motsinger-Reif AA, Hida A, Borsetti HM, Servick SV, Ciarleglio CM, Robbins S, Hicks J, Carver K, Hamilton N, Wells N, Summar ML, McMahon DG, Johnson $\mathrm{CH}$ : Shift work in nurses: contribution of phenotypes and genotypes to adaptation. PLoS One 2011;6:1-12.

24 Harrington JM: Health effects of shift work and extended hours of work. Occup Environ Med 2001;58:68-72.

25 Lichstein KL, Stone KC, Donaldson J, Nau SD, Soeffing JP, Murray D, Lester KW, Aguillard RN: Actigraphy validation with insomnia. Sleep 2006;29:232-239.

26 Sadeh A, Acebo C: The role of actigraphy in sleep medicine. Sleep Med Rev 2002;6:113124.

27 Tepas DI, Barnes-Farrellb JL, Bobkoc N, Fischerd FM, Iskra-Golece I, Kaliternaf L: The impact of night work on subjective reports of well-being: an exploratory study of health care workers from five nations. Rev Saúde Pública 2004;38:26-31. 